current flows thru the smaller coils making magnetism that unites with the magnetism of the large. coil (which is energized all the time by being across the supply circuit usually 110 volts, 60 . cy.) eddy currents are set up in the aluminum disk causing it to turn at a speed directly proportional to the energy passing.. The holes in the disk open circuit the very small eddy currents caused by the potential coil, preventing more than a half revolution when no energy is being consumed in the circuit.

The magnets of very ligh grade steel are necessary to regulate the speed of the disk for accurate measurement and to maintain the speed directly proportional to the evergy passing. There is in addition a small device to overcome by a little additional torque the inherent friction or incrtia of the disk so that very small loads can be accurately recorded.

The dial or register of a meter is read identically as that of a gas meter from right to left setting down first units then tens, etc. This is necessary especially for the amateur as alternate pointers on the dial rotate oppositely in direction.

\title{
The Foot Candle Meter
}

\section{E. Cogin, Generai Electric Co.}

The foot candle meter, based on an instrument devised by Dr. Clayton H. Sharp, has been developed to meet the demand for a light, compact, non-complicated instrument, which would measure' the illumination intensities commonly found in artificial lighting installations. An instrument so simple that anyone could operate it; so light and compact that it could be carried anywhere; so small that readings could be taken where a large photometer could not be used and sufficiently accurate to be of real practical value. The meter is 6 inches by 8 inches by 1 inch, and weighs only three and one-half pounds.

The basic principle on which the foot candle meter operates is very simple and may be readily demonstrated by means of a piece of white cardboard containing a small opening over which has been placed a piece of white tissue paper. If the cardboard is held between the eye and a light source, the tissue paper spot will appear brighter than the white cardboard. On the other hand, if the 
spot is viewed with the eye on the same side of the cardboard as the light source, the spot will appear darker than the white cardboard. If the illumination on both sides of the cardloard is the same; the tissue paper spot and the cardboard will appear to be of the same brightness.

The above principle is applied to the foot candle meter in the following way. Instead of cardboard and tissue paper, the screen consists of a piece of clear glass on which are two thicknesses of paper, the one which contains the round holes being opaque; and the other highly translucent. This sereen forms one side of the

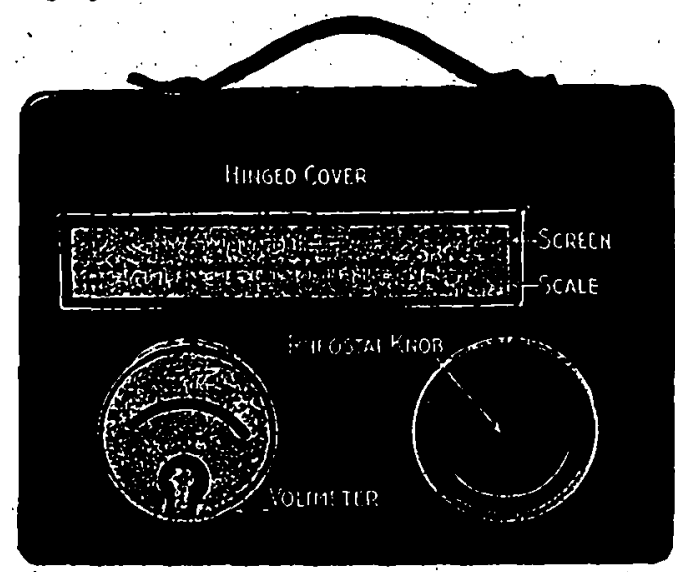

Fis. I.

FRONT VIEI OF THE FOOT. CANDLE METER

light box which is so constructed that the screen is illaminated from within to a much higher intensity at the right end than at the left. The exposed side of the screen is very nearly uniformly illuminated by the light to be measured, and the round spots appear brighter than tho surrounding screen at the right end and darker at the left. It is evident that at the point where the spots change from brighter than their background to darker, the illumination on both sides of the screen is approximately the same, as shown by the cardboard illustration. When the instrument has once been calibrated, the illumination intensity indicated on the screen may bo read at a glance.

If readings of daylight intensities are taken, it may be found somewhat difficult to determine the points at which the spots change 
from lighter to daiker. This is because of the color difference between daylight and the light inside the light box. Under lighting furmished by MIAZDA lamps, where the foot candle meter will be most commonly used, readings can be made mucl more easily and accurately.

It is obvionsly important that after the foot candle meter has been calibrated, the light supplied to the screen from within must be constant, otherwise all readings will be in error. $A$ rheostat or an

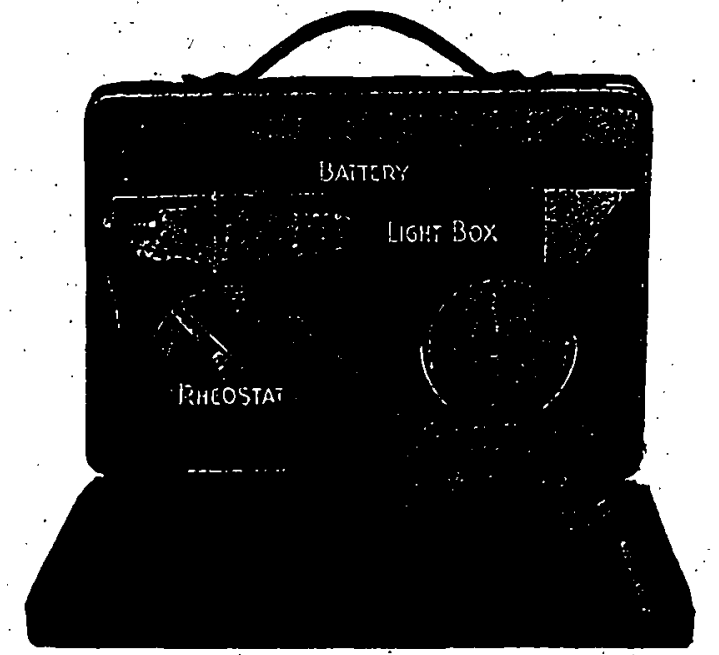

FiE. II.

INTERIOR VIEW FROM REAR WITH A PHANTOM VIEW OF THE LIGHT BOX

adjustable resistance is connected in series with the lamp and battery. This permits the voltage applied to the lamp to be maintained at a constant value as the battery gradually depreciates. 'The voltmeter registers the voltage supplied to the lamp, and as long as the voltmeter needle is directly over the arrow on the yoltmeter scale, the lamp is operating at the correct voltage to supply the proper illumination to the photometric screen. In order to read lower intensities a 1-10 calibration mark is also put on the voltmeter. When a voltmeter needle is set at the $1-10$ mark, read the scale as usual and then divide the readings by ten.

The battery used in the meter is the ordinary three cell flashlight type and may easily be replaced when it becomes too weak to bring the voltmeter needle up to the calibration mark. Replacing a battery will not affect the calibration of the instrument. 
The lamip used in the light box is a special lamp and this cannot be replaced without recalibrating the instrument.

In measuring illumination intensities, the operator should bear the fact in mind that his shadow, if allowed to fall on the instrument, will affect the reading to a considerable extent.

An important consideration in using the foot candle meter is to take care of the screen. This should always be clean and white. Dust or finger marks: on the sereen will impair its accuracy quite materially.

\section{Some Easily Prepared Insecticides}

Chinues H. Strone, Exgilish High School, Bostos.

During the time that our country ha's been at war with Germany, the public attention has been directed, as never before, to the question of food production: To a great many people, agriculture has taken on an entirely new aspect. 'Tens of thousands of school children have enltivated hundreds of acres of ground and have produced a very large amount of various foodstuffs. It is to be hoped that this interest in a good work may continue.

But the experience of a few weeks often convinees the embryo agriculturist that it is not enough to prepare the ground, to plant the seed, and to cultivate the growing plant. A host of insect enemies make their appearance as soon as the plant pushes its tiny green form above ground, and they continue their devastative work until the destruction of the plant is accomplished, unless their own destruction is brought about in some swift and certain way.

It would seem appropriate, then, not only to direct efforts of the child agriculturist in the growing of food plants, but also to call his attention to some of the simple and easily prepared insecticides in common use. The following three are not dangerous to make or to handle, and may be made by any one.

Kerosene Emulsion. Weight out one gram of finely shaved soap and transfer to a flask containing 8 grams hot water. Shake gently until the soap is all dissolved. Then slowly add $16 \mathrm{cc}$. kerosene with shaking until the oil has been completely emulsified. The resulting emulsion may now be diluted with water to any desired degree: The emulsion is then sprayed upon the vines or bushes.

It should be noted that there are two classes of insects for which 